\title{
Impact of subclinical hypothyroidism treatment in systolic and diastolic cardiac function
}

\author{
Impacto do tratamento do hipotireoidismo subclínico \\ na função cardíaca sistólica e diastólica
}

Ricardo Mendes Martins', Regina Helena Alves Fonseca², Marta Maria Turano Duarte $^{2}$, Vaneska Spinelli Reuters', Márcia Martins Ferreira', Cloyra Almeida ${ }^{3}$, Alexandru Buescu', Patrícia de Fátima dos Santos Teixeira', Mario Vaisman'

1 Endocrinology Service, Hospital Universitário Clementino Fraga Filho, Universidade Federal do Rio de Janeiro (HUCFF/UFRJ)

${ }^{2}$ Cardiology Service, HUCFF/UFRJ

${ }^{3}$ Instituto de Psiquiatria

(IPUB), UFRJ
Correspondence to:

Ricardo Mendes Martins Serviço de Endocrinologia, Hospital Universitário Clementino Fraga Filho

Rua Professor Rodolpho Paulo

Rocco, 255

21941-913 - Rio de Janeiro, RJ, Brazil rmendesmartins@gmail.com

Received on 1/Mar/2011 Accepted on 24/Sept/2011

\begin{abstract}
Objective: To evaluate the effects of levothyroxine (L-T4) replacement in echocardiographic parameters of middle-aged women with subclinical hypothyroidism (SH). Subjects and methods: This was a randomized, double-blind, placebo-controlled study. Echocardiographic evaluation was carried out at baseline and one year after restoration of euthyroidism. Thirty-three women with SH were assigned to one of two groups (L-T4 or placebo). Results: The two groups had similar basal characteristics. There was a significant deterioration of left ventricular Tei index after one year of placebo use, which differed from the effect of L-T4 replacement $(+0.086 \pm 0.092$ vs. $-0.014 \pm 0.012 ; p=0.047)$. There was also a slight reduction in cardiac output and cardiac index with placebo use, which was not different from L-T4 effect. Conclusion: Results suggest a positive impact of L-T4 replacement in cardiac function of middle-aged women with $\mathrm{SH}$. Arq Bras Endocrinol Metab. 2011;55(7):460-7
\end{abstract}

Keywords

Hypothyroidism; thyroxine; echocardiography; Doppler; cardiovascular disease

\section{RESUMO}

Objetivo: Avaliar os efeitos da reposição de levotiroxina (L-T4) nos parâmetros ecocardiográficos em mulheres de meia-idade com hipotireoidismo subclínico (HS). Sujeitos e métodos: Realizado estudo duplo-cego, controlado com placebo com avaliação dos parâmetros ecocardiográficos no início e um ano após o restabelecimento do eutireoidismo. Trinta e três mulheres foram incluídas em dois grupos (uso de L-T4 ou placebo). Resultados: Os dois grupos tinham características basais similares. Houve uma significativa piora do índice TEl do ventrículo esquerdo no grupo que usou placebo por um ano. Já no grupo em reposição com L-T4 observou-se uma leve melhora desse índice $(+0,086 \pm 0,092$ vs. $-0,014 \pm 0,012 ; p=0,047)$. Ocorreu também uma leve redução no débito cardíaco e no índice cardíaco com placebo, os quais não diferiram do efeito da reposição de L-T4. Conclusão: Os resultados sugerem um impacto positivo com a reposição de L-T4, na função cardíaca de mulheres de meia-idade, com HS. Arq Bras Endocrinol Metab. 2011;55(7):460-7

Descritores

Hipotireoidismo; tiroxina; ecocardiografia; Doppler; doença cardiovascular

\section{INTRODUCTION}

$\mathrm{T}$ he impact of subclinical hypothyroidism $(\mathrm{SH})$ on left ventricular diastolic and systolic function has been studied by several authors using Doppler echocardiography and exercise performance (1-5).
The most common findings are alterations of left ventricular diastolic function, represented by a prolonged isovolumetric relaxation time (IRT), and an abnormal time-to-peak filling rate when compared with controls subjects (6-9). Left ventricular diastolic dys- 
function may lead to increased morbidity, exercise intolerance and diastolic heart failure $(10,11)$.

The impact of $\mathrm{SH}$ in systolic function is controversial, since studies which evaluated this parameter by Weissler's method demonstrated normal results (12-14). More sensitive echocardiographic methods, especially during stress, were able to demonstrate that patients with $\mathrm{SH}$ showed deterioration of systolic function in comparison with control subjects (11-15).

Myocardial performance index (Tei index) is a simple, noninvasive and reproducible method for the evaluation of systolic and diastolic ventricular function. It is derived from the formula: (isovolumetric contraction time [ICT] + isovolumetric relaxation time [IRT])/ejection time. Several studies have documented that the Tei index is independent of arterial pressure, heart rate, ventricular geometry, atrioventricular valve regurgitation, and afterload and preload. The index has inverse relationship with the ejection fraction. The superiority of the Tei index is attributed to its ability to reflect combined systolic and diastolic performance (16-19).

The aim of the present study was to evaluate the effects of levothyroxine (L-T4) replacement in echocardiographic parameters of systolic and diastolic cardiac function at rest, in middle-aged women with subclinical hypothyroidism, especially using the Tei index.

\section{PATIENTS AND METHODS}

\section{Subjects}

SH female patients were selected from the outpatient clinic of Hospital Universitário Clementino Fraga Filho (HUCFF) at Universidade Federal do Rio de Janeiro (UFRJ). Inclusion criteria were two serum evaluations with thyrotropin (TSH) levels higher than the upper limit range $(4.0 \mu \mathrm{UI} / \mathrm{mL})$, and normal free thyroxine (FT4) levels $(0.9-1.8 \mathrm{ng} / \mathrm{dL})$. Diagnosis had to be confirmed at least six weeks between the two measurements. Patients signed a written informed consent form to take part in the study, which was approved by the Ethical Committee of the institution.

Hypertensive and diabetic patients, as well as those under treatment with drugs that may influence thyroid function were excluded from the study. Patients with serum TSH greater than three times the upper limit of reference $(>12.0 \mathrm{mUI} / \mathrm{mL}$ ) were also excluded.

\section{Study protocol}

Serum TSH, FT4 and antibodies anti-thyreoperoxidase were measured at baseline in each patient. After that, hormonal profile (serum TSH and FT4) was assessed at two-month intervals, until restoration of euthyroidism, and then again, in the end of the study.

After clinical evaluation, patients were randomly assigned to L-T4 replacement or placebo use. L-T4 and placebo pills were similar in appearance and all patients received the same amount of pills. Randomization was carried out after patients were stratified in different groups according serum TSH groups: Level 1, TSH > $4.0-8.0 \mu \mathrm{Ul} / \mathrm{mL}$; and Level 2, TSH > $8.0-12.0 \mu \mathrm{Ul} /$ $\mathrm{mL}$. Then, they were given the initial dosage of L-T4 or placebo, depending on their serum concentration of TSH: $25 \mathrm{mcg}$ for Level 1 and $50 \mathrm{mcg}$ for Level 2.

All patients returned after two months for dose adjustment and evaluation of adherence to the protocol. A nonblinded endocrinologist performed clinical reevaluations and was responsible for adjusting the dose. After that, patients had their serum TSH and FT4 levels measured every three months. If an adjustment in the dose was necessary, the interval was not considered as time of euthyroidism. The same process of evaluation and "dose adjustment" was used in the placebo group. Echocardiographic evaluation was done at baseline and after one year of euthyroidism.

Throughout the study, exclusion criteria were: development of systemic hypertension, cardiac arrhythmia, or any disease that may influence thyroid function. Patients that did not adhere to the protocol (repeatedly returning more than $20 \%$ of the tablets during the period), and patients that needed doses higher than 75 $\mathrm{mcg}$ to restore euthyroidism were also excluded. At the end of the study, nine patients remained in the L-T4 group, and thirteen in the placebo group.

\section{Evaluation method}

Echocardiographic evaluation was carried out with Siemens G-60, using a transthoracic multifrequency probe. The most commonly used frequency was $3.2 \mathrm{MHz}$, with the harmonic function enabled. The patient was analyzed in left lateral decubitus.

Patients of the two groups were submitted to two-dimensional transthoracic color Doppler echocardiogram, performed by one only echocardiographist, who was blind to both treatments.

The following measurements were determined by echocardiography: left and right ventricle cavity dimen- 
sions in systole and diastole (SLVD and DLVD); left atrium (LA); aortic root diameter (AO); left ventricle mass (LVM), and parameters of systolic and diastolic function. Left ventricular hypertrophy was defined as left ventricular mass index $\geq 110 \mathrm{~g} / \mathrm{m}^{2}(20)$.

Parameters of systolic function were: left ventricle volume (SLVV) in milliliters $(\mathrm{mL})$; left ventricle systolic diameter (LVSD) in millimeters ( $\mathrm{mm}$ ); ejection volume in $\mathrm{mL}$; ejection fraction in $\%(\mathrm{EF})$; fractional shortening $(\%)$; ejection time in milliseconds (ET); Isovolumetric Contraction Time in milliseconds (ICT); and cardiac output $(\mathrm{CO})$ in $\mathrm{L} / \mathrm{m}$. Ventricular volume was determined by Tercholt'z formula, and cardiac output was calculated according to the formula: ejection volume $\mathrm{X}$ heart rate.

Specific diastolic function parameters were: left ventricle diastolic volume (LVDV) in $\mathrm{mL}$; left ventricle diastolic diameter (LVDD) in $\mathrm{mm}$; isovolumetric relaxation time (IRT) in $\mathrm{ms}, \mathrm{E}$ wave velocity $(\mathrm{EW})$ in $\mathrm{m} / \mathrm{s}$, A wave velocity $(\mathrm{AW})$ in $\mathrm{m} / \mathrm{s}, \mathrm{E}$ wave to $\mathrm{A}$ wave ratio (E/A), and $\mathrm{E}$ wave deceleration time in ms (DT). Diastolic dysfunction was defined by the presence of at least one of the following parameters: $\mathrm{E} / \mathrm{A} \leq 1.0, \mathrm{IRT} \geq 100$ $\mathrm{ms}$, or DT $\geq 220 \mathrm{~ms}(20)$.

Patients were also evaluated for left and right Tei index, and it was possible to evaluate the diastolic and systolic function at the same time, independent of preload and afterload. The final value of each parameter was the mean of three consecutive measurements (20).

\section{Statistical analysis}

Baseline characteristic were described using Mean \pm Standard Derivation (Median) and proportions. Mann-Whitney test was used to compare continuous and ordinal variables between study groups. Similarly, comparison of proportions was based in $\chi^{2}$ or Fisher's tests.

The first outcome (indication of L-T4 effect) was defined by variations in cardiac function, calculated using the variation between baseline values (before treatment) and values after one year of treatment. L-T4 effect was obtained by comparing the mean variations between the two groups based in a per protocol analysis. We also compared "before and after" means of each variable in each follow-up group (L-T4 or placebo) using Wilcoxon's test. The association between two continuous variables was assessed by Spearman's correlation coefficient.

\section{RESULTS}

Thirty-three women with subclinical hypothyroidism $(\mathrm{SH})$ were included in two prospective groups (seventeen to L-T4 use, and sixteen to placebo use). Table 1 shows comparability between baseline characteristics of the patients in their respective groups. The two groups had similar demographic characteristics, and were well-matched for TSH serum levels, mean BMI, heart rate (HR), systolic (SAP) and diastolic blood pressure (DAP). There were no significant differences between the two intervention groups in respect to baseline echocardiographic parameters (Table 1). No patients showed left ventricular hypertrophy, according to the criterion determined in the study (left ventricular mass index $\geq 110 \mathrm{~g} / \mathrm{m}^{2}$ ).

Throughout the study, eight patients in the L-T4 group and three in the placebo group were excluded from follow-up. Baseline characteristics of the patients that concluded the study is also shown in table l. Two patients in the L-T4 group and one in the placebo group were excluded during the study because they did not adhere to the protocol. Five patients were excluded from the L-T4 group because euthyroidism was not restored with a L-T4 dose of $75 \mu \mathrm{g} /$ day, and one patient in the placebo group developed overt hypothyroidism. Two patients (one in each group) developed systemic hypertension and were also excluded. Despite the exclusion of these patients, groups at the end of the study were similar in respect to baseline characteristics (Table 1).

\section{The effects of the intervention}

At the end of the study, patients in L-T4 use had mean serum TSH of $2.9 \pm 2.1($ median $=2.5) \mu \mathrm{UI} / \mathrm{mL}$, and those on placebo use showed serum TSH of $5.5 \pm 2.0$ $($ median $=5.4) \mu \mathrm{UI} / \mathrm{mL}$. In the evaluation of their baseline serum TSH, only three patients in the L-T4 group and four patients in the placebo group had baseline serum levels higher than $8.0(\mu \mathrm{UI} / \mathrm{mL})$, which demonstrates that the majority of the patients had truly minimal thyroid dysfunction.

Absolute changes in parameters of cardiac function were calculated for each $\mathrm{SH}$ and placebo patient who completed the follow-up protocol, and were named "delta" $(\Delta)$. Mean variations (or mean $\Delta$ ) in specific diastolic parameters (IRT, E/A and DT) were not statistically significant with L-T4 or placebo use. Also, variations that occurred throughout the stu- 
dy with L-T4 replacement did not differ statistically from those that occurred with placebo use. There was a mild increment in $\mathrm{E} / \mathrm{A}$ in both intervention groups, and reductions in IRT and DT, but with these changes were not statistically significant. There was a modest reduction in LVM after one year of L-T4 use, without statistical significance. A favorable effect detected after L-T4 replacement was the reduction in aortic root diameter $(\mathrm{AO})$, which was significantly different from the increment detected with placebo use (Table 2).

Since the majority of the patients presented at least one abnormal parameter of diastolic function (Table 1 ) at baseline, we evaluated this subgroup of patients for variations in diastolic parameters thoughout the study (Figure 1). In the presence of diastolic dysfunction, L-T4 replacement had a positive impact on aortic root diameter $(\mathrm{AO})$, and a less significant impact in LVM, compared with the placebo. A significant reduction in DT was also detected with $\mathrm{SH}$ treatment, despite not different from the placebo effect. No significant impact of LT-4 replacement was detected in IRT and E/A, despite the non-significant reduction throughout the study. The frequency of patients with diastolic dysfunction at the end of the study was $44.4 \%$ in the treated group, and $46.7 \%$ in the placebo group.

Table 1. Baseline characteristics of patients initially randomized to the intervention groups and of patients that concluded the study, according to the intervention group (placebo or L-T4 use)

\begin{tabular}{|c|c|c|c|c|}
\hline & \multicolumn{2}{|c|}{ Patients initially randomized ${ }^{\star}$} & \multicolumn{2}{|c|}{ Patients that concluded the study* } \\
\hline & L-T4 $(n=17)$ & Placebo $(n=16)$ & L-T4 (n = 9) & Placebo $(n=13)$ \\
\hline Age (years) & $49.9 \pm 9.3(49)$ & $44.6 \pm 8.1(45)$ & $51.7 \pm 10.2(49)$ & $44.4 \pm 8.9(44)$ \\
\hline $\mathrm{TSH}(\mu \mathrm{Ul} / \mathrm{mL})$ & $7.6 \pm 3.6(7.2)$ & $7.9 \pm 3.2(6.8)$ & $8.6 \pm 3.1(8.4)$ & $8.2 \pm 3.4(7.8)$ \\
\hline $\mathrm{BMI}\left(\mathrm{kg} / \mathrm{m}^{2}\right)$ & $27.3 \pm 3.2$ & $24.9 \pm 3.8$ & $27.2 \pm 3.8$ & $23.9 \pm 3.0$ \\
\hline $\mathrm{SAP}(\mathrm{mmHg})$ & $116.4 \pm 15.4$ & $114.6 \pm 9.7$ & $116.0 \pm 14.6$ & $115.0 \pm 8.5$ \\
\hline $\mathrm{DAP}(\mathrm{mmHg})$ & $72.1 \pm 12.4$ & $73.1 \pm 8.5$ & $69.7 \pm 14.7$ & $73.0 \pm 6.7$ \\
\hline $\mathrm{HR}(\mathrm{bpm})$ & $64.7 \pm 11.8$ & $69.3 \pm 7.4$ & $61.3 \pm 11.1$ & $67.9 \pm 7.0$ \\
\hline IRT & $96.1 \pm 18.8$ & $93.5 \pm 13.1$ & $94.6 \pm 7.3$ & $91.8 \pm 14.5$ \\
\hline EW & $0.78 \pm 0.12$ & $0.72 \pm 0.27$ & $0.78 \pm 0.1$ & $0.71 \pm 0.3$ \\
\hline AW & $0.63 \pm 0.14$ & $0.64 \pm 0.06$ & $0.59 \pm 0.2$ & $0.62 \pm 0.1$ \\
\hline$E / A$ & $1.3 \pm 0.4$ & $1.4 \pm 0.3$ & $1.42 \pm 0.4$ & $1.36 \pm 0.3$ \\
\hline DT & $243.8 \pm 40.1$ & $231.8 \pm 52.4$ & $229.8 \pm 39.9$ & $228.0 \pm 57.2$ \\
\hline $\mathrm{CO}$ & $3.8 \pm 1.0$ & $4.1 \pm 0.8$ & $4.1 \pm 0.8$ & $4.2 \pm 0.8$ \\
\hline Diastolic dysfunction (\%) ${ }^{\star \star}$ & 81.2 & 75.0 & 66.7 & 76.9 \\
\hline $\mathrm{Cl}$ & $2.6 \pm 0.3$ & $2.7 \pm 0.5$ & $2.6 \pm 0.2$ & $2.7 \pm 0.4$ \\
\hline EF & $0.73 \pm 0.06$ & $0.75 \pm 0.05$ & $0.75 \pm 0.06$ & $0.75 \pm 0.05$ \\
\hline ICT & $52.5 \pm 9.5$ & $50.9 \pm 5.9$ & $51.8 \pm 10.4$ & $52.0 \pm 5.8$ \\
\hline LVFT & $317.4 \pm 32.2$ & $306.2 \pm 21.9$ & $323.5 \pm 25.6$ & $305.7 \pm 20.9$ \\
\hline LDV & $4.4 \pm 0.2$ & $4.5 \pm 0.4$ & $4.5 \pm 0.3$ & $4.5 \pm 0.4$ \\
\hline LA & $3.4 \pm 0.3$ & $3.4 \pm 0.3$ & $3.5 \pm 0.4$ & $3.4 \pm 0.2$ \\
\hline $\mathrm{AO}$ & $2.8 \pm 0.3$ & $2.7 \pm 0.3$ & $2.9 \pm 0.3$ & $2.7 \pm 0.3$ \\
\hline DLV & $92.1 \pm 8.9$ & $99.5 \pm 24.5$ & $97.5 \pm 15.7$ & $96.3 \pm 20.7$ \\
\hline SLVV & $26.6 \pm 11.3$ & $23.1 \pm 7.1$ & $28.6 \pm 14.8$ & $23.0 \pm 6.6$ \\
\hline LVM & $107.7 \pm 28.6$ & $108.8 \pm 21.8$ & $130 \pm 19.9$ & $105 \pm 29.8$ \\
\hline Tei RV & $0.34 \pm 0.15$ & $0.34 \pm 0.14$ & $0.36 \pm 0.16$ & $0.31 \pm 0.15$ \\
\hline Tei RV > 0.4 (\%) & 31.3 & 33.3 & 33.3 & 33.3 \\
\hline Tei LV & $0.35 \pm 0.13$ & $0.37 \pm 0.09$ & $0.40 \pm 0.1$ & $0.37 \pm 0.1$ \\
\hline Rei LV > $0.4(\%)$ & 30.0 & 40.0 & 44.4 & 41.7 \\
\hline Tei LV & $0.35 \pm 0.13$ & $0.37 \pm 0.09$ & $0.40 \pm 0.1$ & $0.37 \pm 0.1$ \\
\hline
\end{tabular}

p-values obtained in the comparison of each variable at baseline in the L-T4 and placebo group were $>0.100$. ${ }^{*} \mathrm{E} / \mathrm{A} \leq 1.0$ or IRT $\geq 100 \mathrm{~ms}$ or DT $\geq 220 \mathrm{~ms}$. ${ }^{\star *}$ Frequency of patients with at least one of the next abnormal parameters of diastolic function: $\mathrm{E} / \mathrm{A} \leq 1.0$, IRT $\geq 100 \mathrm{~ms}$ or $\mathrm{DT} \geq 220 \mathrm{~ms}$. 
Table 2. Variation in specific parameters of diastolic function, left ventricle mass and aortic root diameter

\begin{tabular}{lccccc}
\hline & \multicolumn{3}{c}{ Variation (mean \pm SD) } \\
\cline { 2 - 6 } & L-T4 & p-value* & Placebo & p-value† & p-valueł \\
\hline$\Delta$ DT & $-9.33 \pm 38.83(-30.0)$ & 0.231 & $-18.77 \pm 60.17(-30.0)$ & 0.437 & 0.684 \\
$\Delta \mathrm{RT}$ & $-5.78 \pm 13.36(-8.0)$ & 0.634 & $-5.15 \pm 23.08(+2.0)$ & 0.196 & 0.943 \\
$\Delta \mathrm{EW}$ & $-0.02 \pm 0.13(-0.01)$ & 0.892 & $0.13 \pm 0.33(+0.03)$ & 0.470 & 0.222 \\
$\Delta \mathrm{AW}$ & $-0.01 \pm 0.14(-0.01)$ & 0.817 & $-0.02 \pm 0.12(-0.04)$ & 0.389 & 0.759 \\
$\Delta \mathrm{E} / \mathrm{A}$ & $0.03 \pm 0.42(+0.04)$ & 0.491 & $0.05 \pm 0.23(+0.04)$ & 0.283 & 0.867 \\
$\Delta \mathrm{LVM}$ & $-1.327 \pm 45.7(-17.0)$ & 0.499 & $+9.5 \pm 32.14(+5.85)$ & 0.305 & 0.351 \\
$\Delta \mathrm{AO}$ & $\mathbf{- 0 . 1 2} \pm \mathbf{0 . 2}$ & $\mathbf{0 . 1 0 2}$ & $\mathbf{+ 0 . 1 2} \pm \mathbf{0 . 3}$ & $\mathbf{0 . 1 8 4}$ & $\mathbf{0 . 0 4 3}$ \\
\hline
\end{tabular}

*: Comparison between before and after means of the L-T4 group (paired test); $t$ : Comparison between before and after means in the placebo group (paired test); $\neq$ : Comparison between mean variations that occurred in the L-T4 and placebo groups.

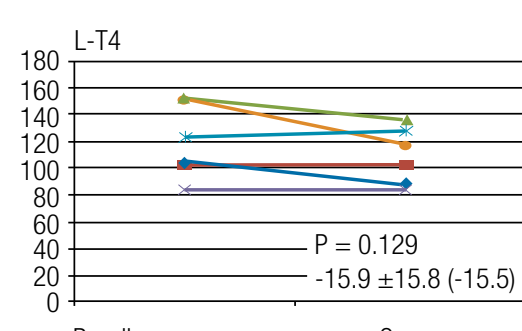

LVM
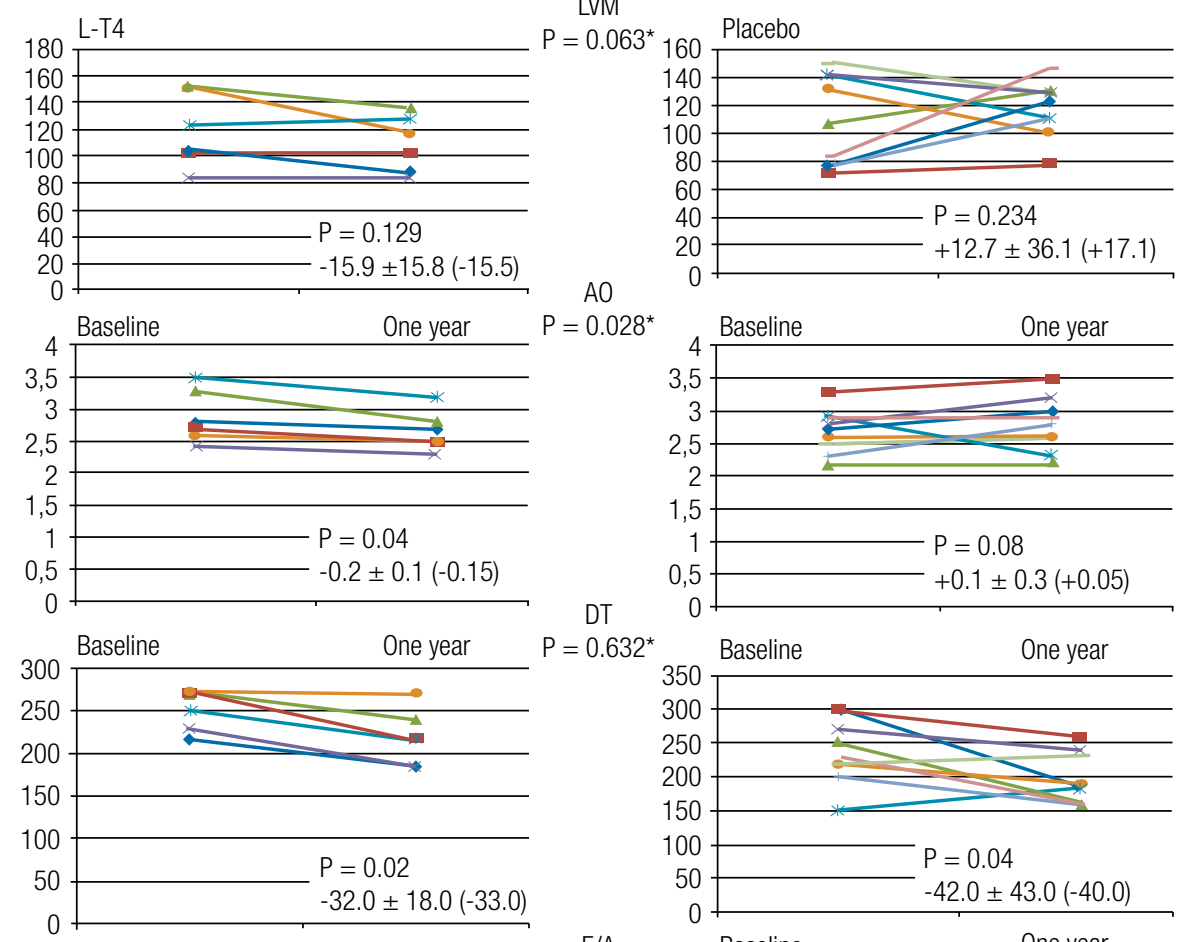

$P=0.632^{*}$
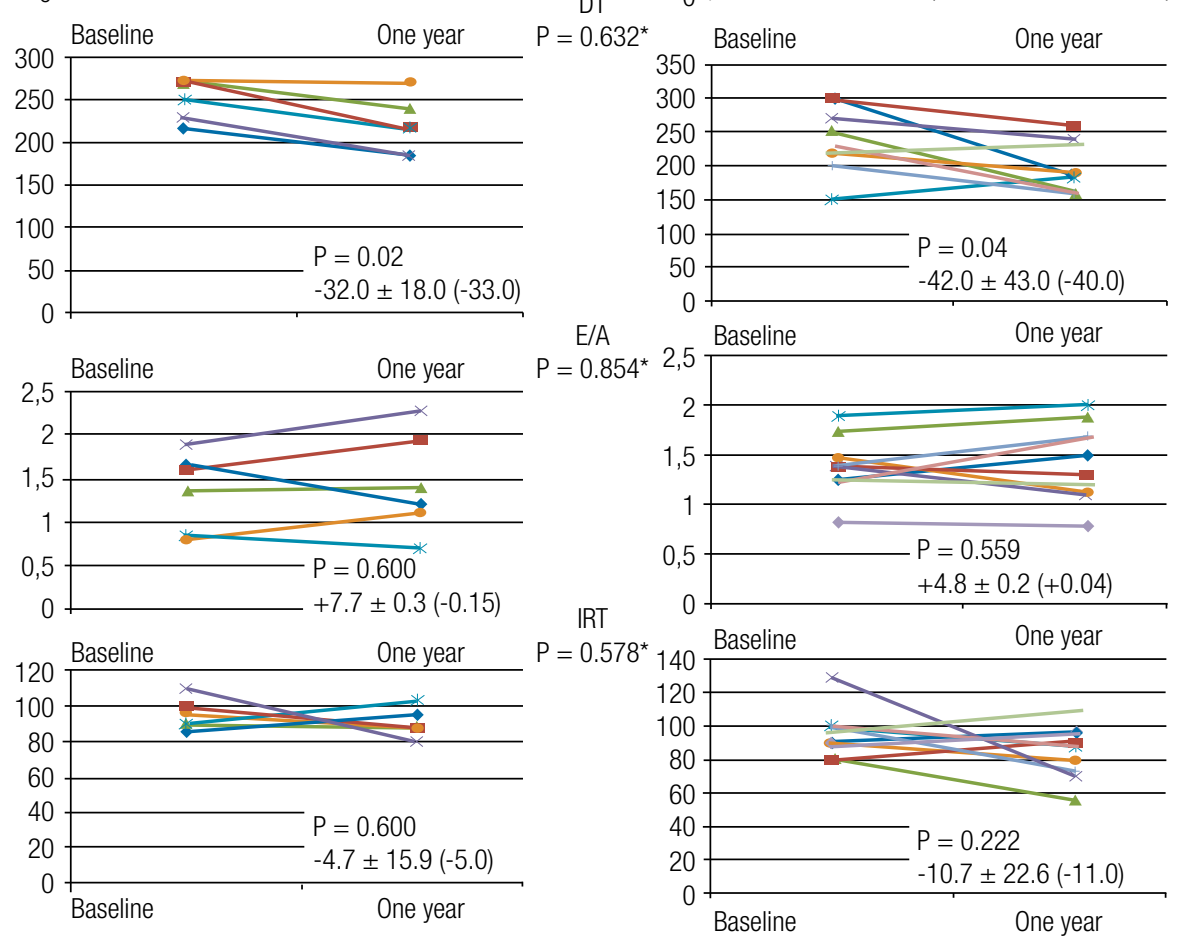

* $\mathrm{p}$-values for the comparisons between the variations with L-T4 replacement vs. placebo use.

LVM: left ventricular mass; AO: aortic root diameter; DT: deceleration time; E/A: E wave/A wave; IRT: isovolumetric relaxation time.

Figure 1. Variations in diastolic parameters of cardiac function in patients with $\mathrm{SH}$ and baseline diastolic dysfunction 
DELTA $(\Delta)$ of Cardiac Output $(\Delta \mathrm{CO})$, Cardiac index $(\Delta \mathrm{CI})$, Ejection Fraction $(\Delta \mathrm{EF})$, Isovolumetric Contraction Time $(\Delta \mathrm{ICT})$, Left Ventricle Filling Time $(\triangle \mathrm{LVFT})$, Diastolic Left Ventricle Diameter $(\Delta \mathrm{DLVD})$, Systolic Left Ventricle Diameter $(\Delta$ SLVD), Left atrium $(\Delta \mathrm{LA})$, Left Ventricle Diastolic Volume ( $\triangle \mathrm{LVDV})$, Left Ventricle Systolic Volume (ALVSV) and Myocardial Performance Index (or TEI index) of right ventricle and Left ventricle are shown in table 3. There was a significant deterioration of the Left ventricular Tei index after one year of placebo use, which differed from the slight improvement that occurred with L-T4 replacement (Table 3 ). The evaluation of frequency of abnormal Left ventricular Tei index $(>0.4)$, at the end of the study, showed a reduction to $25 \%$ in the treated group, compared with an increase (to $61.5 \%$ ) in the frequency of this kind of abnormality in the placebo group ( $\mathrm{p}=$ $0.062)$. Also, the evaluation of the frequency of abnormal Right ventricular Tei index (0.4), at the end of the study, showed similar results: there was a reduction to $25 \%$ in the abnormalities of the treated group compared with an increase (to $46.2 \%$ ) in the frequency of this kind of abnormality in the placebo group $(\mathrm{p}=0.742)$.

There was also a slight reduction in cardiac output and cardiac index with placebo use, which did not reach statistical significance $(\mathrm{p}=0.06)$, and did not differ from the L-T4 effect $(p=0.702)$. The same occurred with Left Ventricle Filling Time, which showed an upwards variation with hormone replacement $(\mathrm{p}=$ 0.07 ), but was not modified with placebo use.

\section{DISCUSSION}

In the present study, the replacement of L-T4 had a favorable impact in the left ventricular Tei index, compared with the deterioration of the $\mathrm{SH}$ group that received placebo. This index reflects both systolic and diastolic ventricle performance (16). The presence of diastolic dysfunction in $\mathrm{SH}$ that is restored after L-T4 replacement has been previously published $(11,15,21,22)$. Earlier, we suggested an association between TSH serum elevation and parameters of diastolic dysfunction, especially DT (23). Despite these previous results, in the present study, L-T4 replacement did not influence those parameters of diastolic function (IRT, DT or $\mathrm{E} / \mathrm{A})$. The reduction in aortic root diameter may reflect an amelioration in aortic complacency and may be associated with better outcomes in diastolic function. Also, reduction in left ventricular mass with the treatment of subclinical hypothyroidism had a positive impact in diastolic cardiac function. However, this last outcome could only be demonstrated in patients with previous diastolic dysfunction.

The increase in the LVFT and the positive impact in LV Tei index may indirectly reflect an improvement of both diastolic and systolic function. The Tei index is easily derived from use of conventional pulsed Doppler echocardiography, as previously described by Tei and cols. (16). LV index $<0.40$ and $<0.30$ for the $\mathrm{RV}$ are considered normal. Higher values correspond to pathological states with overall cardiac dysfunction. There are few studies that used the TEI index in patients with $\mathrm{SH}$.

Table 3. Mean variations (DELTA) in systolic parameters, Tei index, volume and cavity dimensions after one year of L-T4 replacement or placebo use

\begin{tabular}{|c|c|c|c|c|c|}
\hline & \multicolumn{5}{|c|}{ Variation mean \pm SD } \\
\hline & L-T4 & p-value ${ }^{*}$ & Placebo & p-value ${ }^{\dagger}$ & p-value ${ }^{\ddagger}$ \\
\hline$\Delta \mathrm{CO}$ & $-0.091 \pm 1.65(+0.1)$ & $0.953^{\pi}$ & $-0.238 \pm 0.70(-0.28)$ & $0.060^{\natural}$ & $0.302^{\prime \prime}$ \\
\hline$\Delta \mathrm{Cl}$ & $-0.113 \pm 1.08(+0.05)$ & $0.881^{\pi}$ & $-0.170 \pm 0.48(-0.19)$ & $0.05^{\pi}$ & $0.702^{\prime \prime}$ \\
\hline$\Delta \mathrm{EF}$ & $0.014 \pm 0.09(+0.03)$ & $0.654^{\S}$ & $0.003 \pm 0.05(+0.01)$ & $0.835^{\S}$ & $0.724^{\S}$ \\
\hline$\triangle \mathrm{ICT}$ & $-2.00 \pm 8.25(0.0)$ & $0.500^{\pi}$ & $-3.166 \pm 11.58(-7.0)$ & $0.289^{\pi}$ & $0.862 / 1$ \\
\hline$\triangle \mathrm{LVFT}$ & $16.28 \pm 19.68(+24.0)$ & $0.071^{\S}$ & $3.909 \pm 26.74(+14.0)$ & $0.638^{\S}$ & $0.278^{\S}$ \\
\hline$\triangle \mathrm{DLVD}$ & $-0.05 \pm 0.35(-0.1)$ & $0.702^{\S}$ & $0.01 \pm 0.32(+0.1)$ & $0.904^{\S}$ & $0.687^{\S}$ \\
\hline$\triangle S L V D$ & $-0.09 \pm 0.35(-0.2)$ & $0.012^{\S}$ & $-0.02 \pm 0.30(-0.1)$ & $0.013^{\S}$ & $0.658^{\S}$ \\
\hline$\Delta \mathrm{LA}$ & $-0.10 \pm 0.32(0.0)$ & $0.371^{\S}$ & $0.015 \pm 0.27(0.0)$ & $0.843^{\S}$ & $0.372^{\S}$ \\
\hline$\triangle \mathrm{DLVV}$ & $-3.19 \pm 16.85(-5.3)$ & $0.941^{\S}$ & $-2.09 \pm 21.50(-4.1)$ & $0.305^{\S}$ & $0.900^{\S}$ \\
\hline$\triangle S L V V$ & $-6.71 \pm 18.2(-2.4)$ & $0.374^{\S}$ & $+0.26 \pm 6.81(+0.2)$ & $0.807^{\pi}$ & $0.431^{\prime \prime}$ \\
\hline$\triangle R V$ Tei index & $-0.008 \pm 0.02(+0.03)$ & $0.921^{\S}$ & $0.075 \pm 0.021(+0.09)$ & $0.223^{\S}$ & $0.403^{\S}$ \\
\hline$\Delta \mathrm{LV}$ Tei index & $-0.014 \pm 0.01(-0.01)$ & $0.611^{\pi}$ & $0.086 \pm 0.09(+0.063)$ & $0.003^{\pi}$ & $0.047^{\prime \prime}$ \\
\hline
\end{tabular}

*: Comparison between before and after means in the L-T4 group (paired test); ${ }^{\dagger}:$ Comparison between before and after means in the placebo group (paired test); : Comparison between mean variations that occurred in the L-T4 and placebo groups; $\S^{*}: t$ test; ": Mann-Whitney test; ": Wilcoxon's test. 
An increase in systolic left ventricle diameter may be observed with different degrees of systolic dysfunction. The present study detected a reduction in this parameter with L-T4 replacement. This result is in accordance with the slight reduction of cardiac output observed in the placebo group, although not statistically different from the L-T4 effect.

Several studies that evaluated left ventricular systolic function by conventional or tissue Doppler echocardiography at rest detected conflicting results (12-14,21,24-28). Impaired at-rest left ventricular function, as defined by an increased pre-ejection period (PEP)/left ventricular ejection time (LVET) ratio, was reported in some studies using a more sensitive echocardiographic technique in $\mathrm{SH}$ patients, compared with control subjects $(21,24-27)$. However, Tseng and cols. (13) did not find a significant variation in PEP and PEP/LVET by means of concurrent aortic and mitral valve echocardiography.

The limitation of the present study is the small number of participants, and the high number of patients who were lost to follow-up. A possible explanation was the rigid exclusion criteria. The selection of middle-aged women was important to minimize differences in baseline characteristics of both intervention groups, since $\mathrm{SH}$ is more prevalent among women. The two intervention groups were homogeneous in respect to different baseline characteristics.

A high number of patients needed LT4 dosages $>75$ $\mu \mathrm{g} /$ day to restore euthyroidism, which was considered progression of disease. The exclusion of these patients was an important cause of loss to follow-up in this study, and may reflect the necessity of higher doses of levothyroxine replacement even in patients with subclinical hypothyroidism. L-T4 requirements of patients with subclinical hypothyroidism are usually $0.075 \mathrm{mcg} / \mathrm{kg} /$ day. Despite the high number of patients were lost to follow-up, the comparison between the initially randomized group and the group that concluded the study did not demonstrate a selective loss, which could be responsible for imbalance in the randomization characteristics. This fact minimizes the impact of discontinued participation on the final results.

In conclusion, these results suggest a positive impact of L-T4 replacement in cardiac function of middle-aged women with $\mathrm{SH}$, demonstrated by the effects in Left Ventricular Tei index. However, these results should be confirmed in larger trials, and the impact of these findings in patients with other cardiovascular risk factors, or with previous cardiovascular diseases, needs to be explored.

Acknowledgements: We would like to thank Sanofi-Aventis, which supplied L-T4 and placebo pills for the study. There are no conflicts of interest in this study.

Disclosure: no potential conflict of interest relevant to this article was reported.

\section{REFERENCES}

1. Mainenti MR, Vigario PS, Teixeira PF, Maia MDL, Oliveira FP, Vaisman M. Effect of levothyroxine replacement on exercise performance in subclinical hypothyroidism. J Endocrinol Invest. 32(5):470-3.

2. Mainenti MR, Teixeira PF, Oliveira FP, Vaisman M. Effect of hormone replacement on exercise cardiopulmonary reserve and recovery performance in subclinical hypothyroidism. Braz J Med Biol Res. 43(11):1095-101.

3. Arem R, Rokey R, Kiefe C, Escalante DA, Rodriguez A. Cardiac systolic and diastolic function at rest and exercise in subclinical hypothyroidism: effect of thyroid hormone therapy. Thyroid. 6(5):397-402.

4. Caraccio N, Natali A, Sironi A, et al. Muscle metabolism and exercise tolerance in subclinical hypothyroidism: a controlled trial of levothyroxine. J Clin Endocrinol Metab. 90(7):4057-62.

5. Brenta G, Mutti LA, Schnitman M, Fretes O, Perrone A, Matute $\mathrm{ML}$. Assessment of left ventricular diastolic function by radionuclide ventriculography at rest and exercise in subclinical hypothyroidism, and its response to L-thyroxine therapy. Am J Cardiol. 91(11):1327-30.

6. Biondi B. Cardiovascular effects of mild hypothyroidism. Thyroid. 2007;17(7):625-30.

7. Kahaly GJ. Cardiovascular and atherogenic aspects of subclinical hypothyroidism. Thyroid 10(8):665-79.

8. Biondi B, Palmieri EA, Lombardi G, Fazio S. Effects of subclinical thyroid dysfunction on the heart. Ann Intern Med. 137(11):904-14.

9. Fazio S, Palmieri EA, Lombardi G, Biondi B. Effects of thyroid hormone on the cardiovascular system. Recent Prog Horm Res. (59):31-50.

10. Mainenti MRM, Teixeira PFS, Oliveira FP, Vaisman M. Impact of subclinical hypothyroidism in cardiopulmonary response during effort and its recovery. Arq Bras Endocrinol Metabol. 2007;51(9):1485-92.

11. Kosar F, Sahin I, Turan N, Topal E, Aksoy Y, Taskapan C. Evaluation of right and left ventricular function using pulsed-wave tissue Doppler echocardiography in patients with subclinical hypothyroidism. J Endocrinol Invest. 28(8):704-10.

12. Foldes J, Istvanfy M, Halmagyi H, Váradi A, Gara A, Pártos O. Hypothyroidism and the heart. Examination of left ventricular function in subclinical hypothyroidism. Acta Med Hung. 44(4):337-47.

13. Tseng KH, Walfish PG, Persand JA, Gilbert BW. Concurrent aortic and mitral valve echocardiography permits measurement of systolic time intervals as an index of peripheral tissue thyroid function status. J Clin Endocrinol Metab. 1989;69(1):633-8.

14. Staub JJ, Althaus BU, Engler H, Ryff AS, Trabucco P, Marquardt K, et al. Spectrum of subclinical and overt hypothyroidism: effect on thyrotropin, prolactin, and thyroid reserve, and metabolic impact on peripheral target tissues. Am J Med. 1992;92(6):631-42.

15. Arinc H, Gunduz H, Tamer A, Seyfeli E, Kanat M, Ozhan H, et al. Tissue Doppler echocardiography in evaluation of cardiac effects of subclinical hypothyroidism. Int J Cardiovasc Imaging. 2006;22(2):177-86. 
16. Tei C, Ling LH, Hodge DO, Bailey KR, Oh JK, Rodeheffer RJ, et al. New index of combined systolic and diastolic myocardial performance: a simple and reproducible measure of cardiac function--a study in normals and dilated cardiomyopathy. J Cardiol. 26(6):357-66.

17. Lakoumentas JA, Panou FK, Kotseroglou VK, Aggeli KI, Harbis PK. The Tei index of myocardial performance: applications in cardiology. Hellenic J Cardiol. 46(1):52-8.

18. Møller JE, Poulsen SH, Egstrup K. Effect of preload alternations on a new Doppler echocardiographic index of combined systolic and diastolic performance. J Am Soc Echocardiogr. 12(12):1065-72.

19. Bruch C, Schmermund A, Marin D, Katz M, BartelT, Schaar J, et al. Tei-index in patients with mild-to-moderate congestive heart failure. Eur Heart J. 21(22):1888-95.

20. Rakowsky H, Appleton C, Chan KL, Dumesnil JG, Honos G, Jue $\mathrm{J}$, et al. Canadian Consensus recommendations for the measurement and reporting of diastolic dysfunction by echocardiography. J Am Soc Echocardiogr. 9(3):736-60.

21. Yazici M, Gorgulu S, Sertbas Y, Erbilen E, Albayrak S, Yildiz O, et al. Effects of thyroxin therapy on cardiac function in patients with subclinical hypothyroidism: index of myocardial performance in the evaluation of left ventricular function. Int J Cardiol. 95(2-3):135-43.

22. Biondi B, Fazio S, Palmieri EA, Carella C, Panza N, Cittadini A. Left ventricular diastolic dysfunction in patients with subclinical hypothyroidism. J Clin Endocrinol Metab. 84(6):2064-7.
23. Fonseca RHA, Teixeira PFS, Duarte MMT, Vaisman M. Echocardiographic evaluation of left and right ventricular function in subclinical hypothyroidism. Exp Clin Endocrinol Diabetes. 2009;117:324-8.

24. Di Bello V, Monzani F, Giorgi D, Bertini A, Caraccio N, Valenti G, et al. Ultrasonic myocardial textural analysis in subclinical hypothyroidism. J Am Soc Echocardiogr. 13(9):832-40.

25. Vitale G, Galderisi M, Lupoli GA, Celentano A, Pietropaolo I, Parenti $\mathrm{N}$, et al. Left ventricular myocardial impairment in subclinical hypothyroidism assessed by a new ultrasound tool: pulsed tissue Doppler. J Clin Endocrinol Metab. 87(9):4350-55.

26. Monzani F, Di Bello V, Caraccio, Bertini A, Giorgi D, Giusti C, et al. Effect of levothyroxine on cardiac function and structure in subclinical hypothyroidism: a double blind, placebo controlled study. J Clin Endocrinol Metab. 86(3):1110-5.

27. Aghini-Lombardi F, Di Bello V, Talini E, Di Cori A, Monzani F, Antonangeli $L$, et al. Early textural and functional alterations of left ventricular myocardium in mild hypothyroidism. Eur J Endocrinol. 155(1):3-9.

28. Bough EW, Crowley WF, Ridgway EC, Walker H, Maloof F, Myers GS, et al. Myocardial function in hypothyroidism: relation to disease severity and response to treatment. Arch Intern Med. 138(10):1476-80. 